http://jmscr.igmpublication.org/home/ ISSN (e)-2347-176x ISSN (p) 2455-0450 crossref DOI: https://dx.doi.org/10.18535/jmscr/v8i9.37

\author{
Journal Of Medical Science And Clinical Research \\ IGM Publication \\ An Official Publication of IGM Publication
}

\title{
Comparative study of intraarticular steroid injection and normal saline for the treatment of Idiopathic frozen shoulder
}

\author{
Authors \\ Prof. Bashir Ahmed Mir, Dr Hilal Ahmad Kotwal, Dr Mohd Iqbal Wani \\ Postgraduate Department of Orthopaedics, Government Medical College Srinagar J\&K, India
}

\begin{abstract}
Idiopathic frozen shoulder is amongst the common problems in orthopedic outpatient department which is characterized by gradual and progressive pain and stiffness of the shoulder joint followed by loss of motion and finally spontaneous recovery over the period of time. Different modalities of treatment are available for Idiopathic frozen shoulder, but none has got universal acceptability. The purpose of this study was to compare the outcome of intra-articular steroid injection and normal saline.

Methods: This was a comparative study done at Government bone and joint surgery hospital Barzulla Srinagar between April 2019 to April 2020, which included 60 patients with Idiopathic Frozen shoulder. There were 30 patients in each group. The mean age of respondent was 57.36 years. Simple Random method of sampling was adopted for selecting patients for each group. Hydroplasty group was given $30 \mathrm{ml}$ normal saline $4 \mathrm{ml} 2 \%$ Lidocain (plain) and $4 \mathrm{ml} \mathrm{0.5 \%} \mathrm{Bupivacain} \mathrm{(total} \mathrm{volume:40ml)} \mathrm{and} \mathrm{steroid} \mathrm{group}$ was given $2 \mathrm{ml}$ Methylprednisolone, $4 \mathrm{ml} 2 \%$ Lidocain(pain), $4 \mathrm{ml}$ 0.5\% Bupivacain with total volume: 10 $\mathrm{ml}$. Both groups were attached for therapeutic exercises. Comparison of outcomes between two treatment groups was done using Visual Analogue Scale (VAS) for pain, Shoulder Pain and Disability Index for Shoulder function and degree of range of motion.

Statistical analysis was done using SPSS 17.0

Results: There was significant improvement in level of pain, Shoulder function (Shoulder Pain and Disability Index) and range of motion in forward flexion, abduction, external rotation, and internal rotation in four month period in Steroid group compared to normal saline group.

Conclusion: There was a significant improvement in pain, range of movement and Shoulder Pain and Disability Index (SPADI) score in all patients of both group but the difference in improvement was found to be statistically significant in steroid injection group, So steroid injection was found to be more effective treatment modality than normal saline in idiopathic frozen shoulder in short term follow up.

Keywords: Frozen shoulder, Hydroplasty, Intrarticular steroid injection, Shoulder pain and Disability Index.
\end{abstract}

\section{Introduction}

The term Frozen shoulder (Adhesive Capsulitis) is a chronic condition of unknown etiology characterized by gradually progressive, painful restriction of all shoulder joint motion, with slow spontaneous restoration of either partial or complete motion over months to year. Frozen shoulder condition is a chronic fibrosing condition of the capsule of the shoulder joint ${ }^{[1]}$. Idiopathic frozen shoulder is a commonly encountered problem in orthopedic outpatient department. The "frozen shoulder" diagnosis has been used for 
many years in describing shoulder pain and limited motion, and was originally thought to be "periarthritis." Nevasier was the first to identify the pathology through histological and surgical examination of frozen shoulder patients. The condition "Frozen shoulder" is a painful and debilitating condition with an incidence of $3 \%$ to $5 \%$ in the world population and up to $20 \%$ in those with diabetes ${ }^{[2-3]}$ The term 'frozen shoulder' was first introduced by Codman in 1934 to describe \& present a clinical condition that has been of interest to clinicians since the late 1800 s [4]. Codman, when he coined the term 'frozen shoulder', he claimed that this disorder is 'difficult to define, difficult to treat, and difficult to explain from pathology point of view ${ }^{\text {[2]. }}$

Frozen shoulder is an idiopathic disease that presents itself with symptoms such as pain and decreased range of motion (ROM) of the shoulder and shoulder joint capsule fibrosis ${ }^{[5]}$ leading to stiffness and disability. Research suggests that it is known to affect $2 \%$ - $5 \%$ of the general population with majority demographics being patients above 45 years of age, thus affecting individuals that are still working ${ }^{[6]}$. It is more common in women as compared to men ${ }^{[7]}$. Frozen shoulder can be either primary or secondary. Primary frozen shoulder is generally idiopathic while the secondary frozen shoulder is associated with diabetes, hemiparesis, trauma, cardiovascular disease, rotator cuff disease and impingement ${ }^{[8]}$. The treatment for frozen shoulder or idiopathic adhesive capsulitis is controversial. Common treatment options include physical therapy, corticosteroid injections and nonsteroidal anti-inflammatory drugs (NSAIDs). More invasive treatments include capsular distension, manipulation under anaesthesia and arthroscopic capsular release, but are only considered when conservative treatments fail ${ }^{[9]}$. Most patients can be managed with conservative treatment in primary care ${ }^{[5]}$. Intra-articular corticosteroid is widely used as a non-operative treatment for frozen shoulder due to its costeffectiveness and acceptance among patients ${ }^{[10]}$. The purpose of an intra-articular steroid injection is to relieve pain, attempt to reduce synovial inflammation to decrease capsular fibrosis and allow improvement of range of motion ${ }^{[7,11,12]}$.

\section{Materials and Methods}

Patients with frozen shoulder were registered in our hospital from April 2019 to April 2020 and were analysed retrospectively in this study. All patients presenting with a preliminary clinical diagnosis of stage 1 or stage 2 adhesive capsulitis based on the criteria described above were treated with an intra-articular injection of local anesthetic and corticosteroid and normal saline. 60 patients were included in the study and divided into two groups of 30 patients each. 15 patients with stage 1 and 45 patients with stage 2 adhesive capsulitis. There were 26 male and 34 female patients. All patients above 40 years with primary or secondary frozen shoulder with duration of pain more than or equal to two months and that were not responding to physiotherapy were included. Patients with systemic disorders like rheumatoid arthritis, previous history of trauma or surgery to the concerned shoulder, or any bleeding disorder or any recent history of aspirin or aspirin like drug intake or history of diabetes mellitus were excluded from the study. Bilateral cases were also excluded from the study.

We injected the shoulder joint using a posterior approach using a 20-gauge spinal needle with a combination of $2 \mathrm{ml}$ methyl prednisone $(80 \mathrm{mg}$ ) plus $2 \mathrm{ml}(1 \%)$ lignocain (total volume 10ml) in one group and other group was given $30 \mathrm{ml}$ normal saline $4 \mathrm{ml} 2 \%$ Lidocain (plain) and $4 \mathrm{ml} 0.5 \%$ Bupivacain (total volume:40ml). It was an outdoor procedure without any admissions and patients were sent home after 2 - 3 hours of observation. They were advised to do range of motion exercises for quicker recovery. Random blood sugar was done pre-injection in all the patients. All our patients received only one injection. . Range Of Motion, Visual Analogue Scale for pain (VAS) and Shoulder Pain and Disability Index (SPADI) 10 were systematically measured before the procedure and at 1 week, 1 
month and 4 months after the procedure. Statistical analysis was performed using Microsoft Excel. The study was approved by the Ethical Committee.

\section{Results}

60 patients were included in the study out of which 15 patients with stage 1 and 45 patients with stage 2 adhesive capsulitis. 34 (56.67\%) were female patients while $26(43.34 \%)$ were male patients. The ages of the patients ranged from 43 years to 82 years with mean age of 57.36 years. Most of the patient (42\%) was between age group $50-59$ years. Out of 60 patients $42(70 \%)$ had non dominant hand involvement

Table 1 Comparison of Range of Motion (ROM) in Two Groups

\begin{tabular}{|c|c|c|c|}
\hline $\begin{array}{l}\text { Range of motion } \\
\text { assessment }\end{array}$ & $\begin{array}{l}\text { Steroid only } \\
\text { group (mean } \\
\text { increment in } \\
\text { degrees } \pm \text { SD) }\end{array}$ & $\begin{array}{l}\text { Hydroplasty group } \\
\text { (mean degree of } \\
\text { increment } \pm \text { SD) }\end{array}$ & $\mathrm{P}$ value \\
\hline $\begin{array}{l}\text { Pre procedure } \\
\text { forward flexion }\end{array}$ & $79.2 \pm 13.71$ & $81.2 \pm 13.2$ & 0.517 \\
\hline $\begin{array}{l}\text { Forward flexion at } \\
\text { 1week }\end{array}$ & $30.6 \pm 11.2$ & $20.50 \pm 6.81$ & 0.000 \\
\hline $\begin{array}{l}\text { Forward flexion at } 1 \\
\text { month }\end{array}$ & $56.00 \pm 12.2$ & $46.20 \pm 11.0$ & 0.002 \\
\hline $\begin{array}{l}\text { Forward flexion at } 4 \\
\text { months }\end{array}$ & $72.0 \pm 11.5$ & $58.2 \pm 12.0$ & 0.006 \\
\hline $\begin{array}{l}\text { Pre procedure } \\
\text { abduction }\end{array}$ & $58.20 \pm 9.68$ & $63.2 \pm 10.28$ & 0.147 \\
\hline Abduction at 1 week & $37 \pm 5.92$ & $28 \pm 7.2$ & 0.000 \\
\hline Abduction at 1 month & $68 \pm 10.90$ & $56 \pm 11.6$ & 0.001 \\
\hline $\begin{array}{l}\text { Abduction at } 4 \\
\text { months }\end{array}$ & $85 \pm 13.60$ & $75 \pm 13.8$ & 0.002 \\
\hline $\begin{array}{l}\text { Pre procedure } \\
\text { internal rotation }\end{array}$ & $3.64 \pm 1.42$ & $3.14 \pm 1.10$ & 0.193 \\
\hline $\begin{array}{l}\text { Internal rotation at } \\
1 \text { week }\end{array}$ & $3.30 \pm 0.6$ & $2.90 \pm 5.4$ & 0.008 \\
\hline $\begin{array}{l}\text { Internal rotation at } 1 \\
\text { month }\end{array}$ & $6.8 \pm 0.94$ & $5.8 \pm 1.12$ & 0.006 \\
\hline $\begin{array}{l}\text { Internal rotation at } 4 \\
\text { months }\end{array}$ & $8.6 \pm 0.94$ & $5.8 \pm 1.12$ & 0.004 \\
\hline $\begin{array}{l}\text { Pre procedure } \\
\text { external rotation }\end{array}$ & $12.2 \pm 8.6$ & $10.8 \pm 7.5$ & 0.699 \\
\hline $\begin{array}{l}\text { External rotation at } 1 \\
\text { week }\end{array}$ & $10.4 \pm 3.9$ & $6.2 \pm 2.3$ & 0.000 \\
\hline $\begin{array}{l}\text { External rotation at } 1 \\
\text { month }\end{array}$ & $19.2 \pm 4.0$ & $15.2 \pm 4.2$ & 0.001 \\
\hline $\begin{array}{l}\text { External rotation at } 4 \\
\text { months }\end{array}$ & $36.20 \pm 8.5$ & $30.10 \pm 1.10$ & 0.016 \\
\hline
\end{tabular}

We observed gradual improvement in Range of motion from day one to four months. There was significant improvement in steroid group compared to hydroplasty group. Range of movement in both group before the procedure was statistically not significant but after procedure there was statistically significant differences between two groups at day one to 4 months periods ( $\mathrm{P}$ value <.05). 
Table 2: Comparison of Shoulder Pain Disability Index at different time between two groups

\begin{tabular}{|l|c|c|c|}
\hline $\begin{array}{l}\text { Assessment of shoulder } \\
\text { disability }\end{array}$ & $\begin{array}{c}\text { Steroid group (mean } \\
\text { reduction in SPADI } \\
\text { score } \pm \text { SD) }\end{array}$ & $\begin{array}{c}\text { Hydroplasty group(mean } \\
\text { reduction in SPADI } \\
\text { score } \pm \text { SD) }\end{array}$ & P value \\
\hline SPADI pre procedure & $7.21 \pm 0.40$ & $7.20 \pm 0.41$ & 0.24 \\
\hline SPADI 1week & $2.65 \pm 0.53$ & $2.12 \pm 0.63$ & 0.05 \\
\hline SPADI 1 month & $5.30 \pm 0.85$ & $4.61 \pm 0.91$ & 0.048 \\
\hline SPADI 4 months & $6.49 \pm 0.81$ & $5.53 \pm 1.2$ & 0.037 \\
\hline
\end{tabular}

Shoulder Pain Disability Index difference was not statistically significant between two groups before procedure but difference of reduction in the
SPADI score was statistically significant (P value $<.05)$ in one month and 4 month follow up.

Table 3: Comparison of visual analogue scale at different time between two groups

\begin{tabular}{|l|c|c|c|}
\hline Assessment pain score & $\begin{array}{c}\text { Steroid group (Mean } \\
\text { reduction in pain } \\
\text { score } \pm \text { SD) }\end{array}$ & $\begin{array}{c}\text { Hydroplasty group } \\
\text { (mean reduction in pain } \\
\text { score } \pm \text { SD) }\end{array}$ & P value \\
\hline VAS pre procedure & $6.54 \pm 0.82$ & $6.86 \pm 0.71$ & 0.15 \\
\hline VAS 1 week & $2.72 \pm 0.71$ & $2.02 \pm 0.56$ & 0.05 \\
\hline VAS 1 month & $2.62 \pm 0.73$ & $5.02 \pm 0.76$ & 0.04 \\
\hline VAS 4 months & $6.16 \pm 0.53$ & $5.42 \pm 0.84$ & 0.028 \\
\hline
\end{tabular}

Visual analogue scale was not statistically significant between two groups before procedure, which was found to be significant $(\mathrm{P}$ value $<0.05)$ after procedure in 1 month and 4 months period

\section{Discussion}

In our comparative study, total 60 patients who met our inclusion criteria were selected for the procedure. Among the fifty patient $34(56.67 \%)$ were female and 26(43.34\%) were male. Most of the patient $(42 \%)$ was between age group 50-59 years. The mean age of respondent was 57.36 years and $42(70 \%)$ of the patient in this study had non dominant hand involvement.

The staging system for adhesive capsulitis was initially described by Neviaser and Naviaser ${ }^{[13]}$. They suggested four stages that ranged from synovial inflammation with limited motion to adhesive synovitis, to more mature adhesions with less synovitis, and finally to mature adhesions with limited motion.

Dudkiewicz., et al. ${ }^{[8]}$ presented a study in 2004 of 54 patients with mean follow up of 9.2 years. They claimed that conservative treatment for frozen shoulder i.e. physiotherapy and intraarticular steroid injection was an effective long term treatment method. But he did not cover the correlation of the treatment method with the duration of lasting symptoms and patient treatment histories. Hazleman., et $\mathrm{al}^{\left[{ }^{[14]}\right.}$ in his study then summarized numerous research papers on the use of intraarticular corticosteroid injections and concluded that the success rate of the treatment depended primarily on the duration of symptoms. His results suggested that if the treatment was initiated within 5 months from the onset of symptoms then the patients would recover in around 8.1 months.

Bulgen., et al. ${ }^{[15]}$ in his study compared results of patients with frozen shoulder treated with physical therapy, ice, intra-articular steroid injection and benign neglect. He found that the short term results were well in patients with steroid injections, but in long term follow-ups, statistically there was no difference found in pain and ROM of these patients.

Robert G Marx., et al. ${ }^{[4]}$ retrospectively studied patients with stage 1 or stage 2 adhesive capsulitis. He hypothesised that the use of intraarticular corticosteroid injection in the early stages of idiopathic adhesive capsulitis would lead to a rapid resolution of stiffness and symptoms. He too in line with the theory that the treatment option would be decided by the length of symptoms 
suggested that Patients who were treated in stage 1 recovered more rapidly than those in stage 2 and corticosteroid injection in the early stages of adhesive capsulitis allowed the patient to regain motion prior to developing severe fibrosis in many cases.

Sharma RK., et al. ${ }^{[16]}$ in his paper presented 32 patients suffering from frozen shoulder that had not improved with physiotherapy. He treated them by using manipulation under general anesthesia or by steroid injection and hydraulic distension under local anaesthesia. He reported his results and recommended distension technique, as it was easier and gave better results than manipulation. Following this, Singh GP., et al. ${ }^{[17]}$ also studies the benefits of hydraulic distension technique to patients suffering from frozen shoulder. He presented $88 \%$ excellent results with hydraulic distension technique and recommended that patients with frozen shoulder should be treated with hydraulic distension under local anaesthesia with steroid

A study by Mussa M., et al. ${ }^{[18]}$ in 2016 presented a group of 60 patients with idiopathic adhesive capsulitis and compared their preoperative and postoperative scores using VAS Scores. According to their findings the VAS Score improved from 7 pre-operatively to 2 in the 6 months post-operative follow up.

Another study by Rawat MS., et al. ${ }^{[19]}$ conducted in 2018 presented a group of 32 patients with idiopathic adhesive capsulitis and compared their preoperative and postoperative scores using VAS Scores and CSS. According to their findings the VAS Score improved from 7 - 10 pre-operatively to 0 - 3 in the 3 months post- operative follow up and the CSS improved drastically in 3 months. Our study reported the same trend as both these studies with the VAS and CSS score improving from 7.67 and 16.67 preoperatively to 2.89 and 43.41 in their 3 month postoperative follow up respectively. Therefore, our results directly support their inference that Local intra-articular steroid injection is effective in relieving pain and improving range of motion of patients with frozen shoulder. Limitations included that our sample size was small and we did not have a control group. Another limitation of this research is that it is impossible to know with certainty that all injections were indeed intra-articular despite the surgeon being well experienced.

\section{Conclusion}

On the basis of this study we can conclude that, Local intra-articular steroid injection is effective and safe for patients with idiopathic adhesive capsulitis and improves range of motion and relieves pain. Longer follow up period is required to access the benefits of the condition over the Long term. There was improvement in pain, range of movement and Shoulder Pain and Disability Index (SPADI) score in all patients of both group but the difference in improvement was found to be statistically significant in steroid injection group as compared to hydroplasty group. So steroid injection was found to be more effective treatment modality than hydroplasty in treatment of idiopathic frozen shoulder.

\section{Bibliography}

1. Bunker TD, Reilly J, Baird KS, et al. Expression of growth factors, Cytokines and matrix metalloproteinases in frozen shoulder. J Bone Joint Surg. (Br) 2000; 82-B: 768-73.

2. Jacobs LG, Barton MA, Wallace WA, et al. Intra-articular distension and steroids in the management of capsulitis of the shoulder. BMJ. 1991; 302:1498-1501.

3. Rowe CR, Leffert RD. Idiopathic chronic adhesive capsulitis ("frozen shoulder") In: Rowe CR, editor. The Shoulder. New York: Churchill Livingstone; 1988. pp. 155-163.

4. Jacobs LG, Smith MG, Khan SA, Smith K. Manipulation or intra-articular steroids in the management of adhesive capsulitis of the shoulder? A prospective randomized trial. J Shoulder Elbow Surg. 2009; 18:348-353 
5. Diercks RL and Stevens M. "Gentle thawing of the frozen shoulder: a prospective study of supervised neglect versus intensive physical therapy in seventy-seven patients with frozen shoulder syndrome followed up for two years". Journal of Shoulder and Elbow Surgery 13.5 (2004): 499-502.

6. Hsu JE., et al. "Current review of adhesive capsulitis". Journal of Shoulder and Elbow Surgery 20.3 (2011): 502-514.

7. Campbell's operative orthopaedics, volume three/11th edition page: 26252627.

8. Marx RG., et al. "Intraarticular corticosteroid injection for the treatment of idiopathic adhesive capsulitis of the shoulder”. HSS Journal 3.2 (2007): 202207.

9. Guyver PM., et al. "Frozen shoulder - a stiff problem that requires a flexible approach". Maturitas 78.1 (2014): 11-16.

10. Roh YH., et al. "Intra-articular corticosteroid injection in diabetic patients with adhesive capsulitis: a randomized controlled trial". Knee Surgery, Sports Traumatology, Arthroscopy 20.10 (2012): 1947-1952.

11. Gulzar Saeed Ahmed., et al. "Frozen shoulder: Role of single intra- articular corticosteroid injection and home exercise programs". Journal of the Liaquat University of Medical and Health Sciences 10.3 (2011): 138-142.

12. Dudkiewiz I., et al. "Idiopathic adhesive Capsulitis, long term results of conservative treatment". Israel Medical Association Journal 6.9 (2001): 524-526.

13. Neviaser RJ and Neviaser TJ. "The frozen shoulder. Diagnosis and management". Clinical Orthopaedics 223 (1987): 5964.

14. Hazleman BL. "The painful stiff shoulder". Rheumatology and Physical Medicine 11.8 (1972): 413-421.
15. Bulgen Dy., et al. "Frozen shoulder: prospective clinical study with an evaluation of three treatment regimen". Annals of the Rheumatic Diseases 43.3 (1984): 53-360.

16. Sharma RK., et al. "Frozen shoulder syndrome. A comparison of hydraulic distension and manipulation". International Orthopaedics 17.5 (1993): 275-278.

17. Singh GP., et al. "Comparison of intraarticular steroid vs hydraulic distension for the treatment of frozen shoulder". Journal of Universal College of Medical Sciences 1.1 (2013).

18. Mohammad Mussa., et al. "Role of intraarticular steroid injection in the management of idiopathic adhesive capsulitis of the shoulder". International Journal of Contemporary Medical Research 3.11 (2016): 3222-3223.

19. Manvendra Singh Rawat., et al. "Evaluation of the role of intra-articular Steroid injection in frozen shoulder". International Journal of M Orthopaedics Sciences 4.1 (2018): 792-794. 